\title{
TRABALHO DOCENTE E DESAFIOS NA ATUALIDADE: ENTREVISTA COM ÁLVARO MOREIRA HYPOLITO ${ }^{1}$
}

\author{
Magda de Abreu Vicente (UFPel)* \\ https://orcid.org/0000-0003-2583-3263 \\ Iana Gomes de Lima (UFRGS)** \\ https://orcid.org/0000-0002-6386-7248 \\ Marisel Valério Porto (UFPel)*** \\ https://orcid.org/0000-0003-1111-724X
}

\section{RESUMO}

Álvaro Moreira Hypolito é Doutor em Curriculum and Instruction pela Universidade de Wisconsin-Madison e Professor Titular da Universidade Federal de Pelotas (UFPel). 0 renomado professor em pesquisas referentes ao trabalho docente nos concedeu esta entrevista no dia 31 de janeiro de 2019, na Faculdade de Educação da UFPel. Neste texto, Álvaro elucida de forma teoricamente densa, objetiva e clara quais são os desafios do trabalho docente na atualidade. Desafios estes que vêm sendo progressivamente intensificados com as modificações políticas ocorridas no Brasil, principalmente a partir das últimas eleições em 2018. Frente a este cenário, a entrevista aqui apresentada torna-se uma leitura fundamental para os (as) educadores(as). As palavras do referido professor apontam inúmeros desafios para a profissão docente, ajudando na reflexão permanente sobre a densidade e a importância de ser educador(a) na atualidade. Palavras-chave: Trabalho docente; Profissionalização docente; Gestão Educacional; Desafios atuais; Neoliberalismo.

\section{ABSTRACT}

\section{TEACHING WORK AND CURRENT CHALLENGES: AND INTERVIEW WITH ÁLVARO MOREIRA HYPOLITO}

Álvaro Moreira Hypolito is a Doctor of Curriculum and Instruction from the University of Wisconsin - Madison and Full Professor of the Federal University of Pelotas (UFPel). The renowned professor in researches related to teaching

1 Entrevista realizada em 31/01/2019. Álvaro Moreira Hypolito é Doutor (PhD) em Curriculum and Instruction na Universidade de Wisconsin - Madison, professor Titular da Universidade Federal de Pelotas, Coordenador do Programa de Pós-Graduação em Educação e coordenador do CEPE - Centro de Estudos em Políticas Educativas da UFPel. Publicou mais de 64 artigos em periódicos especializados e 47 trabalhos em Anais de eventos. Possui 36 capítulos de livros e 12 livros publicados como autor e/ou editor.

* Doutora em Educação pela Universidade Federal de Pelotas (UFPel). Professora da Prefeitura Municipal de Pelotas. E-mail: magdabreu@gmail.com

** Doutora em Educação pela Universidade Federal do Rio Grande do Sul (UFRGS). Professora Adjunta da Faculdade de Educação da UFRGS. E-mail: iana_glima@yahoo.com.br

*** Mestre em Letras pela Universidade Federal de Pelotas (UFPel). Técnica em Assuntos Educacionais da Universidade Federal de Ciências da Saúde de Porto Alegre (UFCSPA). E-mail: mariselvalerio@hotmail.com 
work granted us this interview on January 31, 2019 at the Faculty of Education of UFPel. In this text, Álvaro elucidates in a theoretically dense, objective and clear way what are the challenges of teaching work today. Challenges that have been progressively intensified due to the political changes that have taken place in Brazil, especially since the last elections in 2018. Given this scenario, the interview presented here becomes a fundamental reading for educators. The words of this professor point out numerous challenges for the teaching profession, helping in the permanent reflection on the density and importance of being an educator today.

Keywords: Teaching work. Teaching professionalization. Educational management. Current challenges. Neoliberalism.

\section{RESUMEN}

\section{TRABAJO DOCENTE Y RETOS EN LA ACTUALIDAD: ENTREVISTA CON ÁLVARO MOREIRA HYPOLITO}

Álvaro Moreira Hypolito es doctor en Currículo e Instrucción por la Universidad de Wisconsin-Madison y Profesor Titular en la Universidad Federal de Pelotas (UFPel). El reconocido profesor en investigaciones relacionadas con el trabajo docente nos concedió esa entrevista el 31 de enero de 2019 en la Facultad de Educación de la UFPel. En este texto, Álvaro explica de manera teóricamente densa, objetiva y clara cuáles son los retos del trabajo docente en la actualidad. Estos desafíos se han intensificado progresivamente con los cambios políticos que tuvieron lugar en Brasil, especialmente desde las últimas elecciones en 2018. Ante ese escenario, la entrevista que se presenta aquí se convierte en una lectura fundamental para los(as) educadores(as). Las palabras de este profesor apuntan a numerosos desafíos para la profesión docente, ayudando en la reflexión permanente sobre la densidad y la importancia de ser un(a) educador(a) hoy em día.

Palabras clave: Trabajo docente. Profesionalización docente. Gestión educativa. Retos actuales. Neoliberalismo.

\section{Introdução}

O trabalho docente e as implicações das políticas governamentais neoliberais na atuação dos profissionais da educação certamente são algumas das questões constantemente estudadas durante a trajetória profissional do professor Álvaro Moreira Hypolito. Ao abordar em seus estudos temáticas relativas à identidade e à autonomia docente, bem como sobre a gestão escolar, este pesquisador posiciona-se frente ao avanço da mercantilização da educação e problematiza o processo de proletarização do professorado e sua crescente desprofissionali- zação, situações que carregam consigo a marca da feminização da profissão e seu constante desprestígio. Tal situação foi perpetuada de modo que características do trabalho docente constantemente foram identificadas com as de um trabalho doméstico, vocacionado, maternal e missionário, o que ajudou a propagar o rebaixamento salarial e, atualmente, o baixo prestígio social que, inevitavelmente, tem levado a categoria ao desgaste profissional.

Assim, o trabalho do professor, Doutor em Curriculum and Instruction pela Universidade 
de Wisconsin-Madison e Professor Titular da Universidade Federal de Pelotas (UFPel), respaldado pelo referencial teórico e metodológico de influência freiriana, neomarxista, e mais recentemente de alguns elementos do pós -estruturalismo, nos conduz a refletir sobre o longo período da história da educação brasileira e suas modificações no processo de trabalho docente, relacionado com as transformações do trabalho na sociedade, assim como sobre as relações de classe, gênero e étnico-raciais, presentes nas políticas governamentais e na organização escolar.

Hypolito teve relevante participação em variados espaços de gestão educacional, atuando em coordenação de cursos, chefia de departamento e do programa de Pós-Graduação da Universidade Federal de Pelotas: vice-direção da Faculdade de Educação, no Programa de Pós-Graduação em Educação, na Pró-reitoria de Graduação (Gestão 2013-2017) e na coordenação da Redestrado - Brasil. Também foi membro da Anped e da ANPAE.

Nesta entrevista, apresentamos o percurso acadêmico-formativo e disposições teóricometodológicas apropriadas pelo entrevistado, no que se refere a uma discussão que consideramos historicamente desafiadora: o trabalho docente e sua profissionalização, especialmente frente ao cenário atual.

\section{A entrevista}

Entrevistadoras: Pelo que estudamos de sua obra, é possível perceber que suas primeiras produções se pautavam em um forte diálogo com a perspectiva teórico-metodológica das teorias marxistas e, ao longo dos anos, o senhor foi incorporando em seus estudos teorias neomarxistas. 0 senhor pode nos esclarecer como estas correntes contribuíram para as suas pesquisas e qual a importância das teorias neomarxistas para o estudo dos atuais fenômenos educacionais, especialmente no campo do trabalho docente?

Álvaro: Quando eu iniciei meus estudos, acho que no primeiro trabalho que eu considero importante, que foi o artigo publicado na revista Teoria e Educação, em 1991, editada pelo professor Tomaz Tadeu da Silva (HYPOLITO, 1991). Ali a abordagem teórica marxista, de alguma forma, tinha um acento muito forte, mas já com indícios de alguma aproximação com o neomarxismo. Principalmente pela incorporação das questões de gênero, incorporação de outros temas culturais que o marxismo de forma mais tradicional não incorporava, por ter uma marca, na tradição da sociologia brasileira, muito forte nos aspectos econômicos e socioeconômicos. Isso foi muito marcante na minha formação, mas já nesse período eu tinha contato, por exemplo, com a obra do Michael Apple, que depois foi o meu orientador de doutorado. Ele tinha publicado algumas coisas no Brasil, principalmente o primeiro livro dele sobre currículo (APPLE, 1982), que trazia uma forte influência da teoria crítica frankfurtiana. Incorporação da teoria crítica, mas, principalmente, com uma influência muito forte da teoria gramsciana. A incorporação da noção de Estado ampliado, a noção de sociedade civil/sociedade política, da importância da sociedade civil nos processos de luta em torno das políticas, das políticas educacionais. Fortemente, a incorporação de ideia de uma autonomia relativa das lutas políticas e sociais em relação a um determinismo socioeconômico. Ao mesmo tempo, esse neomarxismo foi incorporando outras categorias de análise, como a questão de gênero. Teve que incorporar, eu diria melhor, tais categorias em razão da absorção, da assimilação de certos aspectos das lutas culturais que se travaram no final dos anos de 1960 e 1970, que colocaram em evidência os movimentos raciais, de gênero, feministas, que colocavam em xeque a determinação dos aspectos econômicos sobre os processos político-sociais, e que ressaltavam determinadas dinâmicas que estão aí, cada vez mais presentes, como as relações de gênero e as relações raciais. Importantes para uma interpretação das políticas, particularmente, em 
torno das lutas, das políticas mais próximas ao terreno de lutas que é o Estado. Nesse sentido, a própria concepção do Estado se altera para uma arena de lutas, uma arena política de lutas, mais do que a ideia de um Estado hierárquico, verticalizado e dominador, de cima para baixo; não, um Estado que é resultado de ações sociais de luta. Essa visão afetou bastante aquilo que vínhamos estudando como política educacional, particularmente o trabalho docente. 0 trabalho docente é algo que acontece em uma esfera que não é uma esfera somente econômica, mas é uma esfera fortemente cultural. Há aspectos econômicos importantes, fortes, intensos, como é o caso dos aspectos da formação de mão de obra, das questões salariais dos professores, da própria constituição de classe, que são muito importantes e estão presentes em algumas análises com origem no marxismo. Mas há outros aspectos que contrapunham as análises mais tradicionais, as quais ficavam um tanto insuficientes para explicar determinados fenômenos, como, por exemplo, o processo de feminização do magistério. Não o processo de feminização propriamente dito (como aumento do número de mulheres na profissão), mas como esse trabalho se transforma com a incorporação das lutas das relações de gênero no interior do próprio processo de trabalho. Então, aquilo que o Elomar Tambara (2002), que é um professor da UFPel que introduziu essa temática, que é a ideia de que houve não só um processo de feminização do magistério, mas um processo de feminilização, que é a transformação do trabalho que não é só executado por mulheres, mas que passa a incorporar, ao ser executado, algumas características femininas. De modo que tudo isso nos levou - eu digo que nos levou porque não foi um processo individual - a ir incorporando outras teorias para complexificar a análise de um processo que é extremamente complexo.

Entrevistadoras: Em 1999, o senhor escreveu um artigo com um título provocador "Trabalho docente e profissionalização: sonho prometido ou sonho negado?" (HYPOLITO,
1999). Nele, o senhor afirmava que a profissionalização docente era uma condição reivindicativa dos professores e dos reformistas neoliberais, os quais também traziam, desde então, um discurso sobre como devia ser essa profissionalização. Já naquela época, o senhor chamava atenção para os riscos desses discursos reformistas que, atrelados a concepções mercadológicas, culpabilizavam os docentes pelos problemas educacionais e, ao mesmo tempo, apontavam a negação da possibilidade de sonhar. Ainda no mesmo texto, o senhor destacava diferentes resistências a essa precarização, como organizações contra-hegemônicas, compostas por governos da frente popular, ações sindicalistas e experiências docentes emancipatórias. Atualmente, passadas quase duas décadas da tessitura dessa publicação, temos testemunhado um crescente ataque ao sonho da profissionalização, visto o evidente aumento do desprestígio, do desrespeito e, até mesmo, da violência aos docentes. Lamentavelmente, são recorrentes relatos de agressão física aos professores(as), sobretudo da Educação Básica. 0 senhor poderia discorrer um pouco sobre o tema da "desprofissionalização" e dos discursos reformistas neoliberais, considerando esse fenômeno social crescente de ataque à figura desses profissionais e a atuação contemporânea das formas de resistências mencionadas acima?

Álvaro: Bom, é uma pergunta grande e complexa porque trata de vários temas. Eu vou tentar respondê-la por partes. A primeira questão a considerar é que a profissionalização docente sempre veio e esteve presente na reeducação dos professores. Nós temos relatos e estudos que mostram que, pelo menos desde o século XIX, mas mesmo antes disso, os professores começavam a se organizar em alguns países, por meio de associações, muito para se "libertar" do controle da Igreja sobre o trabalho de ensinar. 0 trabalho docente, como se sabe, nos séculos XVIII e XIX, era um trabalho totalmente controlado pela Igreja, principalmente, a Igreja Católica, mas não exclusivamente. No 
final do século XIX, houve embates importantes em associações de professores para lutar por uma condição de profissionalização, isso se deu pari passu, como demonstra o Antônio Nóvoa (1991), concomitantemente com o processo que veio a ser denominado de funcionarização. Processo em que o magistério começou a lutar e a optar por uma condição de profissionalização que passava por um licenciamento atribuído pelo Estado, por meio do qual os docentes passaram a ser funcionários públicos. Isso tinha muito a ver com uma perspectiva liberal/republicana das associações docentes, porque era preferível ser funcionário público de um Estado republicano do que estar atrelado a alguma elite aristocrata, que mantinha relações muito promíscuas com a Igreja. $\mathrm{Na}$ verdade, os professores pensavam em ter mais autonomia profissional, e suas lutas eram por essa demanda. Muitas lutas ocorreram durante todo o século XX por profissionalização, quase sempre com relação mais ou menos direta com o processo de feminização/feminilização, de funcionarização e de proletarização. Até hoje é uma luta que vem se estabelecendo para garantia do processo de funcionarização e profissionalização. Por outro lado, ficou demonstrado por muitas análises, e esta eu acho que foi uma contribuição importante do marxismo, que o professorado passou por um processo de proletarização. A proletarização implica não só um rebaixamento salarial, já que, em algumas épocas, os professores e as professoras tiveram salários comparados ao de juízes e promotores. Ao longo do tempo, os salários foram diminuídos, reduzidos a ponto de provocar uma importante pauperização da categoria. Outro aspecto é que a ideia do prestígio social que a profissão detinha com a sociedade tem a ver com status profissional, que foi sendo perdido. Além disso, houve uma perda do controle sobre o trabalho. É por isso que a análise do processo de trabalho foi uma coisa que me perseguiu muito e está presente até hoje, na interpretação de como o processo de trabalho vai se modificando. É no processo de trabalho que se exerce um controle sobre o trabalho. Na medida em que os professores e as professoras e as escolas foram estabelecendo relações cada vez mais complexas de organização do trabalho, com hierarquias, supervisões, coordenações, e na medida em que foi sendo retirado o controle do corpo docente sobre o que ensinar e como ensinar, há uma perda de autonomia sobre o trabalho, de modo que o controle vai se afastando do trabalhador e passando para alguma instância fora do processo de trabalho. Isso caracteriza a proletarização, não é só o fato de se tornar assalariado. Assalariamento sempre existiu. Aqui importa o fato de $o$ assalariado ser controlado desde fora, com uma perda de autonomia sobre o seu trabalho e a ideia de um prestígio social que também se perde. Quando se fala que os reformistas neoliberais retomam o discurso de que os docentes deviam ser melhores professores, melhores profissionais, é importante mostrar que isso é feito por uma outra via que não é pela via de favorecer as condições reivindicadas pelo magistério, ao contrário, eles vão sempre colocar a culpa sobre o fracasso da educação no corpo docente ou na sua formação e, por isso, há necessidade de mexer na formação dos professores, o que atinge as universidades, os próprios professores e suas estruturas sindicais etc. Quando os reformistas vão buscando soluções, quando analisadas fica demonstrado que nunca são as soluções desejadas pela categoria docente. Ao contrário, são cursos de formação de menor qualidade, cursos mais rápidos, que é o que lutamos contra desde os anos de 1990, para garantir uma formação que seja vinculada às universidades, enquanto essas políticas reformistas pretendem a privatização das universidades, que a formação seja realizada em cursos de curta duração, de finais de semana, e chamam isso de profissionalização. Falam que é uma categoria desprestigiada, o que é verdade, pois tem ocorrido esse desprestígio. No entanto, uma das razões que poderíamos destacar é que isso nunca é solucionado, visado ou pretendido pelas reformas, pois cada vez 
mais os cortes orçamentários para a educação e para os encargos docentes são maiores e, portanto, recursos menores, e nunca se resolve, por exemplo, a questão salarial dos professores. Nos países que resolveram isso de algum modo, as profissões docentes são as mais procuradas pelos jovens, o prestígio social é grande e as condições de trabalho, formação e salário são muito boas. Ontem eu estava lendo uma reportagem, publicada pelo jornal Washington Post (DAM, 2019), que mostra que dos estados norte-americanos em que há dados comparativos sobre emprego e salários, que são 42, somente um estado atualmente está acima da média salarial docente, todos os outros estão abaixo da média. Enquanto nos anos de 1990, eram 26 estados que estavam acima da média no pagamento do salário docente. Isso nos Estados Unidos é um dado recente que mostra que lá houve uma precarização grande. Os Estados Unidos é um país que nós copiamos todos os modelos de reforma, a partir dos modelos deles, e não é um país que tem resolvido a questão educacional, muito ao contrário. Os Estados Unidos é um país que tem estado há muitos anos em posição desconfortável, para dizer o mínimo, quando são divulgados os resultados de exames internacionais para comparação, por exemplo, o Pisa. Os índices educacionais dos Estados Unidos estão sempre do meio para baixo, estáveis há anos, não crescem, não avançam, e nós continuamos a copiar esses modelos.

Nós temos duas situações aí: a trajetória dos docentes para lutar por profissionalização, e não tem conseguido, por isso eu falava que era um sonho prometido e um sonho negado constantemente; e temos essas políticas reformistas que atingem, ofendem bastante as políticas que poderiam favorecer os professores. A gente não tem chegado a muitos lugares.

A Finlândia é um país que eu sempre faço questão de citar, pois os salários pagos aos professores e professoras são um dos melhores salários na sociedade e é a profissão mais procurada pelos jovens nas universidades; a relação candidato/vaga é uma das maiores, maior que o curso de Medicina e outros, porque é uma profissão valorizada pela sociedade. $\mathrm{Na}$ verdade, a luta pela profissionalização não é uma coisa só dos professores, é uma luta que a sociedade também tem que assumir como sua. A Coreia é outro país que tem um salário docente muito bom, a categoria é muito prestigiada. Existem países, como o Japão, em que também há uma consideração muito alta pela categoria docente. Então, é um processo que vem junto, quando o prestígio começa a cair, os salários começam a baixar, a categoria começa a ser desvalorizada, o seu trabalho precarizado, as condições das escolas públicas não melhoram, não tem como falar em profissionalização. Qual é o investimento na escola pública que o Estado faz? Esse investimento não é só salário, mas é muito comum a gente encontrar discursos que dizem assim: "não, salário não adianta, na cidade tal foi melhorado o salário e não resolveu nada"; "veja a cidade tal, a educação melhorou, sem aumento salarial" etc., etc., etc. Claro que não é somente o salário, uma única variável, uma coisa só, mas sem ela não se resolve o restante. Esse era um aspecto da pergunta inicial.

0 segundo aspecto é como o professorado vem resistindo a essa precarização. Eu penso que o movimento docente vem demonstrando, desde os anos de 1980, ser uma categoria muito forte, de oposição às políticas reformistas conservadoras. Nos anos de 1990, início dos anos de 2000, havia um número muito grande de experiências nas redes públicas de ensino, de forte organização sindical, forte luta por democracia escolar. Assim como algumas experiências de educação pública, talvez o termo que pudesse sintetizar isso é a Escola Cidadã, mas havia a Escola Cidadã em Porto Alegre-RS, a Escola Plural em Belo Horizonte-MG, a Escola Candango, que chegou a ter em Brasília-DF, e muitas outras pelo Brasil afora. Eram experiências baseada na gestão democrática, na ideia de articular um currículo conectado com o contexto social das escolas e uma valorização da categoria docente e de trabalhadores 
em educação. Essa valorização nunca ocorreu muito forte, mas chegamos a ter experiências muito boas. Em Porto Alegre-RS, por exemplo, houve épocas em que os professores municipais ganhavam o equivalente a um professor universitário federal. Não sei como está a situação hoje, mas penso que houve uma perda grande em vários sentidos. Mas a organização sindical era muito forte nesse período e a luta por gestão democrática também. Nós temos vários estudos, no nosso grupo, que mostram que as escolas em que os alunos têm boa proficiência são escolas que têm algum elemento importante de gestão democrática (HYPOLITO et al, 2008; HYPOLITO; LEITE, 2012; LEITE et al, 2012). É muito difícil uma escola que não tenha uma proposta, um protejo político-pedagógico, com uma proposta de gestão diferenciada, obter um bom desempenho de seus alunos. Isso é uma coisa importante, mas as experiências de Gestão Democrática atualmente estão praticamente nulas. São experiências formais, eleições para diretores, conselhos escolares, as escolhas ficam aqui e ali e ficam numa lista tríplice, não se avançou nisso. Na prática, os Conselhos Escolares são muito formais e pouco democráticos. Os diretores, mesmo eleitos, são reféns de financiamentos ultracentralizados, e sofrem muita pressão para melhor a qualidade de seus IDEBs. Eu diria assim que, como no campo curricular, o que nós temos observado mais recentemente é um grande avanço das políticas conservadoras. Por exemplo, a questão da Base Nacional Comum Curricular, que praticamente retira das escolas a possibilidade de uma adequação curricular com contexto cultural escolar próprio. Houve muitas experiências que pretendiam ser emancipatórias e, atualmente, penso que sofreram muitas derrotas; hoje o professorado faz uma luta de resistência muito forte para tentar manter alguns avanços obtidos décadas atrás. Vemos algumas ações importantes, por exemplo, o magistério do município de Salvador, na Bahia, se organizou, recolheu todos os materiais pedagógicos que seriam fornecidos para a rede por intermédio de uma parceria com grupo privado, foi lá e depositou todos os pacotes na frente da Secretaria de Educação. É como dizer: "nós não queremos esse material, nós temos currículo para ensinar as crianças." Essa é uma luta em torno do currículo que o Apple fala há muito tempo, em torno do que se organizam várias lutas pelo controle sobre o que ensinar e como ensinar. Esse controle tem em algum momento mais influência neoconservadora, mais influência neoliberal, mais influência das classes médias ou mais influência progressista, e isso vai depender dos embates que ocorrem em cada local, em cada contexto.

Penso já ter comentado o item dois. 0 terceiro aspecto da pergunta se refere à agressão física dos professores da Educação Básica. Isso eu acho que aumenta na medida em que aumenta a pobreza, aumenta na medida em que a escola pública é cada vez mais pobre para as comunidades pobres. É um tema que pouco se discute atualmente no Brasil, mas como é que a gente pode discutir violência no país se a gente não discutir a pobreza? É evidente que a pobreza está associada com a violência. As comunidades mais pobres, muitas vezes, a única forma que encontram de melhorar sua condição de vida é se atrelando ao crime organizado ou praticando coisas que talvez não desejassem. Não podemos ter uma observação moral sobre isso, no sentido de que "é proibido roubar", as pessoas fazem por necessidade. Claro, isso chega a uma falta de controle, como hoje o Brasil, que é desesperadora, nós vivemos quase uma guerra civil. Nós estamos perto da barbárie, muito perto da barbárie, e o que ocorre com a barbárie? Cada um tende a buscar o seu quinhão. Eu acho que isso desestimula muito as escolas. Quando nós temos comunidades com condições de vida muito desfavoráveis, escolas muito desfavoráveis, os professores em condições muito precárias de trabalho, essas relações de violência aumentam, obviamente aumentam. Então, o problema da violência aos docentes está associado ao processo de desprofissionalização, porque é um fenômeno 
cada vez mais crescente e que não acontece em outros lugares/sociedades. Como são esses outros lugares/sociedades? Vivem em condições muito melhores. O Brasil é um dos países mais desiguais do mundo. Ora, se isso não for resolvido, se nós não tomarmos a sério essa discussão que sempre ficamos adiando, falando que "temos que prender o cara que fez o crime", "não adianta ficar discutindo problemas sociais... tem que resolver a violência", deixamos a discussão da desigualdade para trás e nunca a fazemos seriamente. Eu acho que nos últimos anos não conseguimos efetivar isso e é algo que nós temos que enfrentar. Para os professores é algo muito sacrificante, estressante, porque enfrentam uma realidade de trabalho muito ruim, as crianças vivem em condições muito ruins. As relações com a autoridade pedagógica estão praticamente desprivilegiadas. Não com o autoritarismo, mas com a autoridade no bom sentido da palavra, porque, evidentemente, com todas essas denúncias de corrupção, há um mal-estar que estimula a impunidade. Se todo mundo pode fazer, os políticos podem, os governantes podem, e nada acontece, acontece com uns e não acontece com outros e a grande maioria está por aí... 0 Estado parece não ter capacidade de garantir justiça, os corruptores estão todos soltos, os problemas de Brumadinho, Mariana, tudo acontece e o Estado tem pouca capacidade de intervenção e a escola não fica imune a isso.

Isso tudo tem a ver com a questão da desprofissionalização. Há escolas que colocam uma placa na frente, em que os diretores foram quase forçados a fazer uma placa publicando o IDEB da sua escola. Em outras escolas é um processo de humilhação, um linchamento moral dos professores, e isso tem acontecido muito e tem a ver, evidentemente, com uma política de desqualificação nas escolas e, evidentemente, com a política de desprofissionalização docente. Qual a solução dada para melhorar o IDEB e melhor desempenho? São os modelos de pacotes pedagógicos vendidos por instituições privadas, com ou sem fins lucrativos, que apresentam a solução para a melhoria do IDEB. Essa solução é o quê? São pacotes pedagógicos piores que dos anos 1970, em que os professores deverão, para que a escola atinja o IDEB, aplicar os materiais, os professores deverão seguir as indicações daqueles materiais. E isso significa o quê? Significa que, ao fim e ao cabo, a qualificação docente necessária é a qualificação para que o magistério aplique aqueles materiais, o que significa que cada docente pode ser um professor com baixa formação. Por isso, a proposta do Teach for America ou o Educa Brasil, que é associado ao Teach for All, dá uma formação de dois meses e meio, perto de três meses e isso praticamente passa como algum treinamento de formação continuada, acompanhamento continuado durante o exercício, e está solucionado o problema, essa é a grande solução para a escola. Para que ficar formando professores com uma universidade, fazendo pesquisas, discutindo teoria? Como se nós precisássemos de pouca teoria! Nós precisamos de mais teoria na formação e no trabalho. Precisamos de prática, claro que sim, mas não uma prática cega, uma prática orientada teoricamente. Então, nesse sentido, há uma violência moral sobre os professores, é bom destacar isso, pois não há somente uma violência física, dos alunos contra os docentes, que é cotidiana. A violência física está sendo tratada, os alunos que ameaçam estão sendo medicados "adequadamente", ou punidos. Mas as professoras continuam convivendo com essa violência, com uma humilhação moral, social, econômica, de todos os tipos. Eu vejo que a profissionalização é algo ainda muito distante.

Entrevistadoras: 0 trabalho docente não se refere somente ao ato de lecionar, pois, não raro, envolve questões administrativas orientadas pelo gerenciamento governamental. A Gestão Democrática, bandeira de luta da comunidade docente no período da redemocratização no Brasil, prevista em lei desde a constituição de 1988 (BRASIL, 1988) e reforçada pela Lei de Diretrizes e Bases da educação nacional, Lei $\mathrm{n}^{\mathbf{0}}$ 9.394/96 (BRASIL, 1996), tem como principal 
característica a participação da comunidade escolar na tomada de decisões, o que pressupõe, no mínimo, a eleição de seus gestores. No entanto, há uma tendência de reorganização estatal que vem instituindo programas atrelados à administração privada da escola pública, permitindo, por vezes, passar diretamente às empresas a gestão escolar. São as chamadas parcerias público-privadas, já instituídas em algumas escolas e que nos remete à ideia gerencialista. 0 senhor tem trabalhado este tema em diversos textos (COSSIO et al, 2010; HYPOLITO, 2010, 2011, 2014; HYPOLITO; VIEIRA; LEITE, 2012; HYPOLITO et al, 2008; IVO; HYPOLITO, 2015a, 2015b, 2016). Tendo em vista as lutas por uma Gestão Democrática e os tantos percalços enfrentados desde sua implementação, como o senhor analisa o atual avanço da Gestão Gerencialista para o trabalho docente?

Álvaro: Em primeiro lugar, eu queria comentar a primeira frase da pergunta que diz que "o trabalho docente não se refere somente ao ato de lecionar"; isso é bastante importante porque no campo de estudos sobre o trabalho docente há uma polêmica, não bem uma polêmica, mas há um debate em torno do que é o trabalho docente como categoria de análise, inclusive há grupos que preferem usar o termo "trabalho pedagógico" em substituição ao termo trabalho docente ou para expressar o que temos denominado trabalho docente. Eu queria reafirmar a minha posição e a de muitos colegas que trabalham com este tema que é afirmar que o trabalho docente não se refere somente ao ato de ensinar, mas se refere a todo o processo de trabalho escolar em que parte deste processo de trabalho é o trabalho pedagógico, que também não se refere somente ao trabalho de aula, evidentemente. Mas há outros elementos no processo de trabalho que não se referem, exclusivamente, ao trabalho pedagógico. A análise do processo de trabalho com características mais de tradição marxista nos mostra que é preciso que se faça uma análise pormenorizada de todas as etapas do processo de trabalho. É uma análise de economia política que deve considerar diferentes níveis de atuação e é a partir da análise do processo de trabalho que aparece o aspecto da gestão e da gerência no trabalho, enfim, as relações econômicas e políticas de poder e de controle sobre o trabalho. 0 trabalho pedagógico, por mais amplo que seja concebido, é só uma das dimensões do processo de trabalho docente, sob pena de ser alguma outra coisa que não pedagógico.

Ao longo do tempo, eu fui aproximando cada vez mais o tema da gestão, que não era um tema muito presente no meu trabalho, muito embora, desde o início, eu já discutisse alguma coisa, como gerência, a crítica da gerência científica do trabalho, principalmente as críticas ao taylorismo no trabalho escolar; alguma discussão sobre gestão democrática. Atualmente, eu praticamente analiso o processo educativo e o trabalho docente sempre vinculados com os modos de gestão (LEITE; HYPOLITO, 2011) e com as práticas curriculares, as políticas curriculares. Considero uma tríade indissociada que tenho incluído nas minhas análises (HYPOLITO, 2018). Então, como eu vejo o atual avanço gerencialista? Eu falei anteriormente que a gestão democrática hoje para mim é uma quimera, é algo formal, é uma conquista que foi obtida a "duras penas" pelo movimento docente, movimentos sociais e de pais, mas ao longo do tempo foi sendo capturada, colonizada pelos órgãos gestores da educação. De modo que dificilmente encontra-se alguém que vai assumir publicamente uma posição contra a gestão democrática, dificilmente vais encontrar alguém que diga que não pratica a gestão democrática na sua escola, todos afirmam que suas práticas, em todos os níveis da administração, são baseadas na gestão democrática. Mas o que a gente encontra, efetivamente, são alguns elementos daquilo que poderia ser gestão democrática, tipo conselhos escolares, algumas formas coletivas de discussão, eleições para diretor de escola, que a todo momento são combatidas pelos grupos conservadores... Mas, concretamente, o que a gente observa é que muitas 
dessas práticas são meramente formais, isso já foi mostrado em uma das pesquisas citadas, que incluía a análise de diferentes modos da gestão democrática. Talvez uma boa dica seja utilizar a interpretação do Boaventura Santos sobre democracia, experiências de democracia de alta intensidade e democracia de baixa intensidade. Utilizamos essa abordagem para analisar três escolas (LEITE et al, 2012), em pesquisa onde relatamos modelos, análise que, depois, nos fez chegar ao conceito de modos de gestão que utilizamos para interpretar tendências de gestão, para fazer uma tipificação das práticas de gestão escolar. 0 que ocorre? Onde se diz que há gestão democrática, muitas vezes, o que se encontra são princípios da gestão gerencialista. Então, o que mais temos hoje em termos de gestão democrática são os modos de gestão híbridos, formalmente democráticos, em que pode existir eleições para diretores, pode haver conselho de pais, mas a escola não tem autonomia financeira total, não tem controle sobre os recursos que necessita, e tampouco decide o que ensinar e como ensinar. As práticas da gestão gerencialista são cada vez mais presentes. E como isso funciona? Funciona com a aplicação de dois tipos de modelos de privatização, aquilo que Stephen Ball trabalhou em vários textos, a privatização endógena e a privatização exógena. Não é uma privatização propriamente dita, não significa que a escola foi vendida para o setor privado, não é disso que se trata. É uma forma de privatização em que o modelo das formas de gestão é copiado de modelos da administração privada, são trazidos para o interior da escola pública, modelos de gestão com nuances da qualidade total, modelos de financiamento, contratos que a própria escola tem que efetivar com o Estado para cumprir metas. É a privatização de serviços que a escola antes exercia com trabalhadores públicos que passam a ser exercidos como serviços externos, tipo: a terceirização da merenda, a terceirização da portaria, da vigilância; terceirização de serviços de produção de material pedagógico, de uso de material pedagógico.
Em alguns casos já há no Brasil a privatização da gestão pública da escola, que passa a ser exercida por meio de contratos realizados com empresas que vão gerir a escola ou empresas que vão fornecer aplicativos, plataformas, que fazem toda a função administrativa da escola. Isso afeta diretamente o trabalho docente, dita como os professores e as professoras têm que ensinar, o ritmo com que têm que ensinar, quais conteúdos têm que ser ensinados e avaliados. Há estados em que isso já está muito avançado, mas está avançado também em outras redes pelo país afora. É por isso que há interesses muito grandes de grupos econômicos, que estão presentes nas parcerias público-privadas, o que tem sido estudado por vários grupos de pesquisa de universidades brasileiras. Quais são essas parcerias? Basicamente, no Brasil, são representados pelo Todos pela Educação, mas são variados institutos e fundações, a maioria com fins lucrativos, ou tipo Filantropia 3.0, que fornecem esses materiais para as escolas, consultorias, ou fornecem as tecnologias para as escolas como a grande solução para resolver o problema da qualidade da escola, para resolver o problema da qualidade da administração, que é um problema identificado como muito sério, e eles têm o modelo bom para isso ou um modelo para preparar os alunos para o sucesso nos exames nacionais padronizados. Sair bem nos exames é elevar a nota do IDEB. A média brasileira do IDEB está altíssima, estamos muito perto da Finlândia, para ser irônico. Caso atinjamos a média seis estaremos muito perto da Finlândia... Eu estive na cidade de Sobral, no Ceará, que eu não vou analisar aqui pois não tenho dados suficientes, mas lá, por exemplo, há escolas com nota nove; essa escola é "muito melhor" do que a escola da Finlândia, entre aspas, é claro. Ela está preparando para os exames, preparar para o exame é uma coisa, formar as crianças com uma qualidade de cidadão é outra. Esse modelo gerencialista está tão presente nas escolas de hoje que quando a gente vai entrevistar uma diretora, uma professora, dificilmente vai encontrar alguém 
que seja contra a avaliação, pois esse discurso gerencialista vai se incorporando ao comportamento do corpo docente e de diretores. Isso ocorre de várias formas, por meio de políticas indutivas do Estado, "pressão" mesmo em cima dos diretores para a melhoria do IDEB, pressão dos diretores nas escolas, além de formas de "facilitação" na aprovação. Houve relatos em uma pesquisa qualitativa realizada em vários estados, relatos de docentes afirmando algo do tipo: "aqui, na nossa rede, há políticas claras de facilitação da aprovação, para melhorar o fluxo, para melhorar o IDEB", isso é muito aparente. Faz-se tantas recuperações quantas forem necessárias, faz isso, faz aquilo etc.

Aqui há um aspecto interessante. Quando eu falava, lá no início da entrevista, da tradição marxista e neomarxista, quero também apontar uma aderência a alguns aspectos do pós-estruturalismo, porque eu acho que a lei do valor é uma das coisas mais atuais e algo que não se pode contestar na elaboração da teoria marxista, que é algo absolutamente atual. E, inclusive, nos serve muito para analisar os processos de trabalho docente atuais e, como já se viu antes, novas formas de organização do processo de trabalho, baseadas nessas parcerias público-privadas e numa forma de "exploração" do trabalho que é muito grande. Pois a escola, embora pública, passa claramente a desempenhar funções de lucro, não para ela, mas para os agentes privados das parcerias. Então, esse é um aspecto importante. Outro aspecto é o cultural, que nós tratamos, que o neomarxismo trouxe da relação com o Estado e, por isso, a gente incorpora na nossa análise, tanto falando das lutas de professores, da gestão democrática, assim como da oposição às ações gerencialistas. 0 Stephen Ball e outros autores trazem um tema que é muito importante, que é a performatividade, que é um aspecto de que existe um processo de subjetivação que essas políticas vão produzindo e elas fazem com que os discursos sejam subjetivados pela docência; se a gente quisesse usar um pouco da teoria do ator-rede, poder-se-ia até pensar que as pró- prias estruturas, determinados processos que não são indivíduos, coisas, as políticas em si, os documentos, também geram subjetividade sobre nós. Quando endereçam determinados conceitos, metas, metas gerencialistas, os exames, as estatísticas, o IDEB etc. como verdades. Tudo isso vai produzindo um resultado, um desempenho, uma performance desejada para os docentes. As escolas, a partir de determinada orientação político-gerencial, devem assumir um modo de ser que é o modelo gerencialista. Esse modelo vai se incorporando de tal forma que passa a ser assumido com algo necessário, como algo que deve ser feito. Muitos docentes questionam, o movimento sindical questiona e, por isso, são tão odiados pelas políticas conservadoras. Esse tipo de análise, eu diria, é uma contribuição do pós-estruturalismo. É algo que absorvo e incorporo nas análises das políticas. A meu ver, se ficarmos restritos às análises marxistas e neomarxistas, chegaremos a um ponto em que há uma insuficiência interpretativa. Eu poderia reduzir esses aspectos da performatividade, do discurso, ao conceito de ideologia, mas acho que é um pouco mais que isso. Acho que é um domínio que gera uma outra economia política, produz um sujeito, fabrica um sujeito que não tem, muitas vezes, ingerência sobre isso. São aspectos que não são admitidos até pelas lutas sindicais, pelas lutas políticas tradicionais dos docentes, pois é possível que muitos sindicatos considerem que a avaliação é uma coisa boa e não entram no mérito, ficam somente na crítica periférica da avaliação. Há um texto de Popkewitz e Lindblad (2016) que trabalha com estatísticas, números e mostra como isso vem se incorporando na formação dos sujeitos, nesse momento. Por tudo isso que eu penso que a escola pública praticar ou uma gestão democrática ou uma gestão gerencialista tem uma interferência muito grande no processo de trabalho docente, no fazer docente e na sua formação.

Entrevistadoras: Em um dos seus escritos, o senhor defende que o Estado é um agente regulador das políticas educacionais "de modo 
enfático e centralizado, muito embora [haja] o discurso do Estado mínimo e descentralizador" (HYPOLITO, 2010, p. 1338). Segundo seus argumentos, o Estado orienta, define e controla os conteúdos escolares e as metodologias de ensino, figurando-se, assim, como um forte agente fiscalizador e regulador, uma vez que traça diretrizes curriculares, incentiva modalidades menos ortodoxas de educação (EaD, por exemplo) e pauta-se por avaliações educacionais externas e internas. Desse modo, no atual cenário político brasileiro, de que forma é possível analisar a ação do Estado mediante políticas recentes, como a Base Nacional Comum Curricular e a Reforma do Ensino Médio - Lei no 13.415/2017 (BRASIL, 2017)?

Álvaro: 0 Estado é o agente regulador, centralizador, de alguma forma cada vez menos presencial, mas cada vez mais presente, é um ausente-presente. Como isso era feito no século XIX, início do século XX? Um inspetor escolar visitava as unidades escolares, observava o trabalho dos professores na zona rural, nas escolas urbanas e fazia seus relatórios. Os relatórios eram trazidos para a administração central, os professores podiam ser promovidos, podiam ficar no mesmo lugar que estavam ou poderiam ser punidos e até mesmo demitidos. Era um controle direto do Estado sobre as escolas, mesmo com os grupos escolares do início século XX também se fez isso através de inspetores escolares que iam nas escolas, faziam a verificação se estava tudo em dia, batiam o terror na secretaria das escolas, mas era isso. Atualmente, esse inspetor está retornando, mas não mais aquele inspetor para discussão em cada escola, mas inspeciona regiões, estuda as metas, estuda o IDEB, estuda se as metas estão sendo atingidas ou não. Era um pouco isso o que Michael Apple já tratava quando falava do conhecimento oficial e da necessidade que as reformas conservadoras têm tido de definir o currículo nacional. Há vários textos dele tratando disso e é o debate que vimos fazendo, desde os anos 1990 para cá, sobre o currículo nacional. No Brasil, esse debate também ocor- reu muito no campo do currículo, iniciou-se mais fortemente com o documento dos Parâmetros Curriculares Nacionais; há muitas análises críticas sobre tal política, mas ela se efetivou e, posteriormente, foi sendo sucedida pelas diretrizes curriculares nacionais e, mais recentemente, agora definitivamente, substituída pela Base Nacional Comum Curricular.

Entrevistadoras: É um problema os Parâmetros Nacionais?

Álvaro: Nós já discutimos que não havia necessidade de uma definição nacional porque não era tanto os Parâmetros, mas a gente ia numa escola e perguntava "vocês já leram o documento dos Parâmetros? Não." Nunca leram. Então como é que os Parâmetros se efetivavam? O MEC só aprovava livros didáticos que cumprissem os Parâmetros. A efetivação está muito na forma de os livros trazerem uma orientação e, assim, os Parâmetros iam se validando. Tudo está muito articulado mesmo a uma outra coisa, que na época não estava muito articulada, que é a ampliação dos exames nacionais. Havia um sistema de avaliação, que era o SAEB, mas era amostral, com outras pretensões, agora é censitário e pretende individualizar os dados. Depois, foram sendo criados outros exames que a gente conhece, o ENEM, Prova Brasil etc. $\mathrm{Na}$ verdade, isso inclui tanto a Base Nacional Comum Curricular quanto os Parâmetros, só que a Base Nacional Comum Curricular é muito mais definida do que os Parâmetros. Os Parâmetros foram produzidos por colegas nossos e alguns defendiam muito os Parâmetros dizendo que eles não eram currículo nacional, eram meros parâmetros, que foram elaborados por pares etc. e tal. Todavia, quem os elaborou não tinha controle sobre a abordagem que os concebia e articulava.

O interesse de grupos neoliberais e conservadores, principalmente aqueles interessados nas parcerias público-privadas, ou interessados no mercado educacional, que é uma grande economia política, que precisa ser melhor analisada, e que indica ser de interesse mercadológico muito grande, é um dos maiores negócios hoje 
no Brasil, está no controle sobre a Educação e sobre o que acontece no interior da educação. Um pouco aquilo que a gente tem afirmado: $o$ objetivo de toda reforma é alcançar a sala de aula, o cotidiano da sala de aula; se a reforma não alcança, ela não se realiza; por vezes alcança mais, alcança menos, alcança um pouco, quanto mais alcançar, mais ela se efetiva. Para chegar à escola, a reforma tem que ter controle sobre a gestão escolar, tem que ter controle sobre as políticas de Estado em diferentes níveis, que é aquilo que o Bernstein já nos ensinou, também discutindo currículo, discutindo a ideia de currículo nacional, mostrando que as políticas são recontextualizadas em diferentes níveis, o que nos ajuda a observar algumas razões pelas quais as políticas nem sempre chegam às escolas como foram pensadas.

Pretendo voltar nisso, mas, principalmente aqui, quero dizer o seguinte: houve o fato de que esses grupos conservadores nunca desistiram, nunca descansaram enquanto a Base Nacional Comum Curricular não foi aprovada. Eles perseguiram isso. 0 Apple ressalta que a direita tem sido persistente, que os conservadores são persistentes e radicais, pegam uma ideia e vão adiante sem arredar pé de certos princípios e nós, às vezes, digo, o pensamento de esquerda, muitas vezes somos negligentes em alguns aspectos e achamos que as coisas vão se processar de forma mais flexível e tranquila, mas não é assim. Na verdade, essas políticas foram definidas articuladamente, tanto a Base Curricular como a Reforma do Ensino Médio, que está baseada numa base curricular, foram baseadas em uma ideia que é de restringir as áreas de conhecimento às áreas do Enem, muito embora sejam mostradas como ampliadoras de conteúdos, mais democráticas por nivelarem todos os estudantes. 0 Ensino Médio vai passar por um empobrecimento curricular trágico, eu acho. Julgo que é a pior experiência que talvez tenhamos no ensino médio porque a tendência é empobrecer o conhecimento de química, de física, de matemática e das outras áreas, como música, artes, história, geografia.
O foco será só nos exames e no conhecimento instrumental. Mas, por que isso é importante para a reforma? É importante porque se há um currículo nacional, como tu avalias se esse currículo está sendo efetivado? Por meio dos exames, ora. 0 Estado não vai à escola, articula e elabora os exames. 0 Estado regulador, que está muito presente, cada vez mais presente, é um Estado "ausente". Monitora a distância os exames, por intermédio de um sistema de avaliação. E como se pode garantir que a BNCC ajuda com os exames e mostra que o sistema vai bem? A melhor solução, aparentemente, para o mercado, com um interesse neoliberal forte nisso, é a venda dos materiais pedagógicos preparados diretamente para a obtenção do sucesso nos exames e a concretização da Base Nacional Comum Curricular e do IDEB. Essa é uma lógica que julgo perversa, mas é uma lógica que tem essa tríade, que tenta funcionar: com as consultorias privadas no campo da gestão, no campo do currículo e no campo da formação e identidade docente. É extremamente difícil a escola se movimentar nesse meio, porque além dessas avaliações nacionais periódicas, as escolas podem ter, o que é cada vez mais comum, avaliações locais feitas pelas prefeituras com as suas próprias provas. Há, por assim dizer, um enxame de avaliações que os professores passam a sofrer e a ter que focar no cotidiano de ensino. Há inúmeros relatos de escolas que dizem "não, antes dos exames nós aumentamos a carga horária de matemática e português e diminuímos a de Educação Física, de outras áreas". Dizem abertamente isso, por quê? Porque estão neuróticos, obsessivamente orientados a fazer com que a escola melhore 0 IDEB, melhore o desempenho.

Entrevistadoras: E senhor acha que isso corrobora com o que o atual Ministro da Educação ${ }^{2}$ tem falado de uma universidade para a elite e a escola de educação básica pública para a maior parte da população, levando cada vez mais a uma segregação social?

2 Na época da realização da entrevista, o Ministro da Educação ainda era Ricardo Veléz Rodriguéz. 
Álvaro: Ele tentou retificar, tentou dizer que foi mal interpretado na primeira afirmação e que o que ele quer é uma escola básica de qualidade e que se o aluno tiver uma escola básica de qualidade, isso é democracia, segundo ele. Porque se o aluno está bem preparado, ele vai chegar na Universidade, ele vai obter a sua vaga. Não precisa o Estado se meter nisso.

Entrevistadoras: Mas nós vamos ter uma diferenciação aí entre escolas privadas e públicas?

Álvaro: Não sei como o Ministro vai pensar esta questão, mas é nítido que ele não vai ampliar vagas nas Universidades Públicas, isso parece claro. A política do MEC é extremamente conservadora nos aspectos culturais, em princípio parece que não há contradição alguma com a Base Nacional, mas há conflitos internos no MEC, que podem estar mostrando que os neoconservadores, neoliberais e ultraliberais estão em conflito. Assim como o Ministro da Economia é ligado a interesses familiares da educação privada, há grupos que querem uma orientação bíblica para o currículo e para o projeto educacional. Aí parece existir um choque entre interesses neoconservadores e interesses neoliberais.

0 mercado educacional vai ser incentivado, vai ser muito incentivado. 0 que vai ocorrer é um empobrecimento das escolas pobres, empobrecimento curricular e das práticas, daquilo que vai chegar às escolas, ao cotidiano da sala de aula, além das mensagens conservadoras que já pretendem chegar às escolas. É claro que podemos utilizar o conceito de recontextualização do Bernstein, que o Stephen Ball adota de alguma forma quando trata dos contextos da política, do ciclo de políticas, quando trata dos contextos, e é uma ideia que eu absorvi bastante no meu trabalho. Como essas políticas vão ser recontextualizadas em níveis locais, de prefeituras, em redes estaduais e nas escolas? É claro que há um campo de ação para o professorado, não há garantias de que as políticas vão se realizar como foram pensadas. Mas é uma luta difícil que o professorado vai ter que empreender para garantir que o Ensino Médio mantenha alguma qualidade, mesmo com todas as características que estão delineadas, como a privatização, além daquele notório saber, trabalho que pode ser realizado por alguém que não tenha formação docente, tudo isso de fato é outro aspecto da desprofissionalização que se faz presente. Então, na verdade, tudo está muito interligado.

Entrevistadoras: Recentemente, tivemos um período complexo de eleições no Brasil. A ascensão ao poder de partidos de extrema direita é uma realidade que aparece tanto em governos com predomínio de problemas econômicos, como naqueles com estabilidade financeira, da América à Europa. Desde a década de 1980, Michael Apple (2000, 2003), por exemplo, vem estudando os grupos conservadores no contexto estadunidense. Por meio de tais estudos, o autor desenvolveu o conceito de "modernização conservadora", que se constitui em uma aliança entre diferentes grupos com ideais que, ainda que soem modernizantes - como no caso dos neoliberais -, são conservadores (APPLE, 2000, 2003). Nos últimos anos, alguns autores publicaram estudos que indicam a presença de ações de grupos neoconservadores no cenário brasileiro (BARROCO, 2015; MOLL, 2015). Tais autores afirmam que se vive no Brasil uma onda conservadora, presente em diferentes áreas, e que é crescente o movimento de grupos de direita no contexto brasileiro, dentre eles movimentos conectados ao neoliberalismo e ao neoconservadorismo. Cientes de que, atualmente, o senhor tem se dedicado a estudar algumas políticas neoconservadoras, como analisa a chegada de grupos direitistas e conservadores ao poder e de que forma a ascensão desses grupos pode impactar o trabalho docente?

Álvaro: Eu acho que algo que devemos considerar, e que é importante, é que alguns falam da ascensão desses grupos no Brasil, mas eles já estão presentes há muito tempo no cenário político-social. No entanto, eram grupos pequenos, com pequeno grau de influência, mas 
articulados já em diferentes questões. Algumas mais específicas, eu diria tópicas, como, por exemplo, a questão da ideologia de gênero, que cresceu assustadoramente como discurso, mas que teve origem, na verdade, no Vaticano. 0 termo foi formulado no Vaticano quando começa uma ação conservadora para rediscutir aspectos das relações de gênero, das relações de desigualdade de gênero, das discussões sobre identidade e diferentes identidades de gênero etc. Por ali, começou a se criar um conceito muito conservador e muito forte que assumiu vida própria, mas poucos se dão conta de como foi criado. Hoje é um conceito assumido fortemente por grupos religiosos aqui no Brasil, exatamente porque entra numa questão que é sensível a muitas famílias tradicionais e grupos conservadores religiosos. Ao mesmo tempo em que houve um embate político e um crescimento social sobre as discussões de identidade das minorias. A escola tem que ficar atenta aos problemas que surgem no seu cotidiano, na vida das crianças, relativos a essas diferenças e políticas afirmativas, práticas de bullying, uma série de coisas que a escola tem que enfrentar. Começou a existir um embate muito sério entre esses grupos. Muitas discussões e lutas se deram, mas não só os grupos religiosos conservadores cresceram no Brasil. Eu dei o exemplo de identidade de gênero, da ideologia de gênero, mas na verdade é algo que não se constitui numa ideologia de gênero, mas o que os conservadores querem é que não se discuta esses aspectos. Eu queria destacar o seguinte: os grupos direitistas cresceram e, como diz o Apple, eles são persistentes. Mas é um pouco mais do que isso. Em inglês pode-se fazer um jogo de palavras, que o Apple utiliza, que ajuda a entender como crescem alguns desses tipos de pensamento. Apple afirma que as coisas não têm só bad sense e good sense, "senso ruim" (insensatez) e "bom senso", o que não dá o mesmo jogo de palavras como ocorre em inglês. $O$ que ele quer dizer com isso? Nem tudo o que os conservadores fazem é bad sense, insensato, o discurso conservador possui aspectos de good sense, o que permite que esse discurso cresça. Quer dizer que todas as pessoas que aprovaram esses grupos conservadores que chegam ao poder, todas elas são fascistas, neofacistas? Não. Não são. Mas, por alguma razão, os discursos que esses grupos fazem cai num tecido social que estava aberto para ser influenciado. Por que as políticas neoliberais têm obtido êxito há algum tempo? Porque realmente o serviço público foi precarizado, o serviço de saúde é ruim, o serviço escolar em muitos casos é ruim e, para as pessoas comuns, faz sentido criticar esses serviços. Então, quando chega alguém e diz: "a escola tem má qualidade", faz algum sentido esse discurso. Existe uma sensibilidade, existe uma mudança no senso comum, aquele senso comum que circula por aí e que fez com que essas pessoas, digamos, "flutuantes", que querem melhorias na sua vida, mas que não sabem por onde isso vai ser feito, acabem aderindo a essa perspectiva populista de direita, fascista para muitos. Quando esse pensamento consegue se articular e chega ao poder - claro que com alguma manipulação -, vai ter um impacto na educação, vai ter um impacto forte na educação. Por exemplo, a pessoa que foi nomeada agora para ser encarregada da área de formação dos professores do MEC é advogada, não tem nada a ver com a educação, não é professora, nunca estudou para ser professora, e é muito conhecida porque advoga a educação doméstica, a homescholling. Isso é uma coisa que o Apple vem falando há muito tempo e que a gente nunca deu importância no Brasil porque aqui não tinha amparo legal, mas agora esses conservadores querem normatizar a educação doméstica por medida provisória, talvez. 0 que importa é que este debate retorna. Retorna com força. $E$ a pessoa que defende isso está encarregada da formação nacional dos professores. Este tema vai aparecer na formação dos professores, vai retornar. Isso vai ter um impacto grande sobre o trabalho docente. Os aspectos morais do conservadorismo estão presentes atualmente, muito embora alguns deles já caíram, por exemplo, a ideia de ter que 
mudar a moral da política, fazer uma política sem negociação, sem " toma lá dá cá", limpar a corrupção no congresso, dentre outras ideias, já foram pelo ralo, pois os grupos políticos desse conservadorismo têm sido a base dessas políticas e as negociações no congresso já iniciaram. Já está tudo desmontado porque os deputados que foram eleitos por essa linha já estão negociando com a presidência da Câmara, com o Senado, já estão compondo um grupo de apoio, uma aliança política conservadora em troca de verbas, obras etc. A esquerda deve-se questionar muito por que algumas questões não foram efetivadas por uma política progressista no século XX e no século XXI. A esquerda teve oportunidades, algumas coisas melhoraram, em algumas áreas houve um investimento grande, mas aquela que mais avançou - as políticas das minorias - é a mais atacada pelos grupos conservadores e foi nesses embates que esses grupos cresceram, muitas vezes. Mas outras a esquerda nem conseguiu implementar, tais como tornar institucional determinadas mudanças sobre a autonomia escolar (escolha de diretores, por exemplo), a autonomia universitária e a garantia de financiamento para a pesquisa. 0 financiamento da educação sofreu contingenciamentos orçamentários, mesmo que circunstanciais. A sedimentação das políticas de avaliação e de parcerias público-privadas na educação. Nesse tipo de coisa é que não avançamos. 0 impacto sobre o trabalho docente vai ser muito grande, primeiro pelo volume de assertivas conservadoras no conteúdo escolar, uma ofensiva moral para cima dos professores em termos do que eles devem ensinar, o que não devem ensinar, de controle sobre o trabalho docente. Além disso, as políticas de avaliação vão ter continuidade, as provas vão ter continuidade, e essas provas vão ser purificadas porque ainda são muito “ameaçadoras", em alguns aspectos, para as crianças. Assim, alguns temas têm que sair da escola. As políticas conservadoras, neoliberais, não só vão ficar intactas como vão ser aprofundadas. Então, nesse aprofundamento, efetivamente, os professores vão ser os grandes atingidos na escola.

Entrevistadoras: Professor, por último, gostaríamos de agradecer sua relevante contribuição para o debate da temática aqui proposta e de encerrarmos nossos questionamentos retomando suas ideias sobre o trabalho docente e abordando, mais especificamente, o legado de Paulo Freire. Diante do cenário atual, parece oportuno lembrar da importância da obra freiriana e da ampla referência a ela em relevantes trabalhos, como os escritos de Ghiggi (2008), Apple (2011) e Streck (2011). Tendo em vista a reconhecida contribuição teórica, inclusive internacionalmente, de Freire no campo da educação, gostaríamos de ouvir sua opinião sobre os ataques que a figura desse importante pensador brasileiro tem sofrido por parte de grupos direitistas e conservadores e sobre as possíveis repercussões que esse discurso, digamos, "culpabilizador da obra freiriana" pode causar no trabalho docente.

Álvaro: Realmente temos um legado com a obra de Paulo Freire de grande dimensão e repercussão fora do Brasil, no exterior. Ontem eu recebi uma mensagem que dizia que uma escola americana, considerada uma escola modelo, é baseada na filosofia e teoria de Paulo Freire. Mas não é só isso. Paulo Freire é um dos caras mais citados no mundo, é um dos autores mais presentes nos planos de ensino das universidades no mundo. É o único brasileiro que está entre os cem mais citados nos planos de ensino de todas as universidades do mundo. E, na área da educação, está entre os dez mais citados, além de ser traduzido em quase todas as línguas. É Doutor Honoris Causa em dezenas de universidades e por aí vai. Os movimentos sociais que se utilizam de Freire, as escolas que se utilizam de Freire estão espalhadas mundo a fora. Outro dia saiu uma referência na Folha de São Paulo sobre uma escola de São Paulo que é considerada de referência e está toda baseada em Freire. Para iniciar, querer acabar com isso é puro discurso ideológico. Muitos que propagam essas ideias nunca leram um livro ou 
um texto de Freire. É uma idiotice de quem não tem discernimento. Talvez onde Freire menos tenha entrado foi na escola pública brasileira, algumas de suas ideias entram, mas sua repercussão foi maior na formação. Atualmente estuda-se muito pouco Paulo Freire nas Universidades. Então, que medo é esse que eles têm ao ponto de querer varrer Paulo Freire? Tem uma grande influência de Freire na educação brasileira que traz a ideia da prática dialógica, que as coisas sejam conversadas, que não sejam feitas a priori. Mas dentro da própria esquerda brasileira há debates sobre isso; nos anos 1980, havia um debate enorme entre a pedagogia dos conteúdos e a pedagogia libertadora. Freire entra na formação dos professores e nesse ideário pedagógico mais amplo, mas eu acho que precisaria mais. Há escolas se saindo muito bem no IDEB que trabalham com Freire. Então, qual é a retórica contra o Freire? Por onde o Freire entrou nos Estados Unidos? Principalmente, no início, pelos movimentos feministas. É difícil encontrar um livro de educação americano que não cite Paulo Freire. Quando eu iniciei meu doutorado, foi o ano em que Paulo Freire morreu, 1997, eu estava nos Estados Unidos. A biblioteca da Faculdade de Educação da Universidade de Wisconsin inaugurou uma placa em homenagem a Paulo Freire, na época. Isso dias depois de sua morte. Nesta faculdade só havia uma placa que celebrava um educador daquele estado, e depois a de Freire. Então, na época eu sugeri que um pequeno auditório que se instalava na minha faculdade recebesse $o$ nome de Paulo Freire e esta proposta não teve recepção. Eu acho que no fundo essas campanhas contra Freire são um ataque ao que ele foi e representa. Um ataque dos conservadores a algumas repercussões que pode ter o trabalho do Freire, principalmente no cotidiano escolar, quando questões proibidas são discutidas, o conservadorismo tem medo da democracia, medo da discussão porque o Paulo Freire é um autor extremamente democrático com tudo o que pensa, por alguns até criticado por ser democratista, mas é tudo focado na ideia de cidadania, nos grupos sociais, nas lutas contra todas as formas de opressão. Este debate é um bode expiatório, um inimigo eleito para focar naquilo tudo que representa o pensamento crítico, progressista, democrático e de esquerda na educação. É o mesmo que dizem de varrer o marxismo da universidade. Conta-se nos dedos quem é marxista nas universidades. Nem na Filosofia. Há alguns dias ouvi uma entrevista de um professor da Filosofia dizendo que ninguém ali estudava o marxismo. Vejam que isso tudo é uma loucura. É a preparação para um terreno de caça às bruxas. Os caras confundem e nem sabem o que é um pensamento de esquerda e querem achar um bode. Nesse grupo que assumiu o poder tem gente que é "terraplanista", gente que acha que a terra é plana. É uma coisa da Idade Média. É isso que estamos enfrentando. Para mim é um orgulho muito grande defender o trabalho de Paulo Freire, que é uma referência mundial, um clássico aceito por todos. Quem critica nunca leu e nem sabe o que ele escreve ou pensa. Como isso afeta o trabalho docente? O Paulo Freire tem um texto clássico que se chama "Professora sim, tia não". Ali ele fala muito dos aspectos de ser professora, da profissionalização, do gênero, que foi algo que ele assumiu após ter sido criticado pelas feministas americanas por sua linguagem machista, ele passou a escrever sempre professores e professoras e incorporou a crítica e admitiu isso, está escrito. Afeta o trabalho docente exatamente nos pontos que ele falava, na democracia, na autonomia docente, no controle sobre o trabalho, o Estado vai querer dizer o que as professoras devem ensinar e o que não devem ensinar. Já houve censura a um programa chamado Sem Censura, da TV educativa brasileira. A alegação é outra, mas na verdade o programa saiu do ar, é um programa ao vivo. Programas ao vivo podem ser perigosos, as pessoas podem dizer o que pensam. Eu acho que é isso. 0 grande receio que eu tenho dessa onda conservadora sobre o trabalho docente é que o combate ao Paulo Freire é um combate aos professores e às pro- 
fessoras críticos, a docentes que queiram ter autonomia a partir daquilo que acreditam, da liberdade de ensino que é a prerrogativa que têm e podem gozar. 0 meu grande receio é o assédio moral que os professores vão ter, essa é uma grande questão.

\section{REFERÊNCIAS}

APPLE, Michael W. Ideologia e currículo. São Paulo: Brasiliense, 1982.

APPLE, Michael W. Política cultural e educação. Tradução de José do Amaral Ferreira. São Paulo: Cortez, 2000.

APPLE, Michael W. Educando à direita: mercados, padrões, Deus e desigualdade. Tradução de Dinah de Abreu Azevedo. São Paulo: Cortez/Instituto Paulo Freire, 2003.

APPLE, Michael W. Paulo Freire, pedagogia crítica e as tarefas do estudioso crítico ativista. Revista eCurriculum, São Paulo, v. 7, n. 3, p. 1-21, dez. 2011.

BARROCO, Maria Lúcia S. Não passarão! Ofensiva neoconservadora e Serviço Social. Serviço Social \& Sociedade, São Paulo, n. 124, p. 623-636, out./ dez. 2015.

BRASIL. Presidência da República. Casa Civil. Constituição de 1988. Constituição da República Federativa do Brasil de 1988. Brasília, DF, 1988. Disponível em: http://www.planalto.gov.br/ccivil_03/constituicao/constituicao.htm. Acesso em: 20 jan. 2019.

BRASIL. Presidência da República. Casa Civil. Lei no 9.394, de 20 de dezembro de 1996. Estabelece as diretrizes e bases da educação nacional. Brasília, DF, 1996. Disponível em: www.planalto.gov.br/ ccivil_03/leis/19394.htm. Acesso em: 20 jan. 2019.

BRASIL. Presidência da República. Casa Civil. Lei no 13.415, de 16 de fevereiro de 2017. Altera as Leis $\mathrm{n}$ 0 9.394, de 20 de dezembro de 1996, que estabelece as diretrizes e bases da educação nacional, e 11.494, de 20 de junho 2007, que regulamenta o Fundo de Manutenção e Desenvolvimento da Educação Básica e de Valorização dos Profissionais da Educação, a Consolidação das Leis do Trabalho - CLT, aprovada pelo Decreto-Lei no 5.452 , de $1^{\circ}$ de maio de 1943, e o Decreto-Lei no 236, de 28 de fevereiro de 1967; revoga a Lei no 11.161 , de 5 de agosto de 2005; e institui a Política de Fomento à Implementação de Escolas de Ensino Médio em
Tempo Integral. Brasília, DF, 2017. Disponível em: http://www.planalto.gov.br/ccivil_03/_Ato20152018/2017/Lei/L13415.htm. Acesso em: 15 jan. 2019.

CÓSSIO, Maria de Fátima. et al. Gestão educacional e reinvenção da democracia: questões sobre regulação e emancipação. Revista Brasileira de Política e Administração da Educação, v. 26, n. 2, p. 325-341, maio/ago. 2010. Disponível em: https://seer.ufrgs.br/rbpae/article/view/19720. Acesso em: 19 mar. 2019.

DAM, Andrew Van. Public-school salaries fall short of average in nearly every state. The Washington Post, Washington DC, 29 jan. 2019. Disponível em: https://www.washingtonpost.com/us-policy/2019/01/29/what-industry-has-seen-pay-fall -below-average-most-states-public-schools/?utm term=.d872d18900b8. Acesso em: 20 mar. 2019.

GHIGGI, Gomercindo. A pedagogia da autoridade a serviço da liberdade. Diálogos com Paulo freire e formação de professores. 2. ed. Pelotas, RS: Seiva, 2008.

HYPOLITO, Álvaro Moreira. Currículo e projeto político-pedagógico: implicações na gestão e no trabalho docente. Cadernos de Educação, Brasília, DF, v. XVIII, p. 11-26, 2014.

HYPOLITO, Álvaro Moreira. Políticas curriculares, Estado e regulação. Educação \& Sociedade, Campinas, SP, v. 31, n. 113, p. 1337-1354, out./dez. 2010. Disponível em: http://www.scielo.br/pdf/ es/v31n113/15.pdf. Acesso em: 19 mar. 2019.

HYPOLITO, Álvaro Moreira. Reorganização gerencialista da escola e trabalho docente. Educação: Teoria \& Prática, Rio Claro, SP, v. 21, n. 38, p. 1-18, out./dez. 2011.

HYPOLITO, Álvaro M. Trabalho docente, currículo e gestão: trilogia incompleta. Trabalho apresentado no concurso para Professor Titular da Universidade Federal de Pelotas (UFPel). Pelotas, RS, 2018. HYPOLITO, Álvaro M. Processo de trabalho na escola: algumas categorias para análise. Revista Teoria e Educação, Porto Alegre, n. 4, p. 3-21, 1991.

HYPOLITO, Álvaro M.; LEITE, Maria Cecília L. Modos de gestão e políticas de avaliação: entre o gerencialismo e a democracia. In: WERLE, Flávia O. C. (org.). Avaliação em larga escala: questões polêmicas. Brasília, DF: Líber Livro, 2012. p. 135-152.

HYPOLITO, Álvaro Moreira; VIEIRA, Jarbas Santos; LEITE, Maria Cecília Lorea. Currículo, gestão e 
trabalho docente. Revista e-Curriculum, v. 8, n. 2, ago. 2012. Disponível em: https://revistas.pucsp. br/curriculum/article/view/10989. Acesso em: 15 mar. 2019.

HYPOLITO, Álvaro Moreira. et al. Gestão educacional e democracia participativa. Porto Alegre: UFRGS, 2008.

IVO, Andressa Aita; HYPOLITO, Álvaro Moreira. Gestão educacional e o Índice de Desenvolvimento da Educação Básica da rede municipal de ensino de Santa Maria-Rio Grande do Sul. Revista Educação em Questão, v. 52, n. 38, p. 163-192, maio/ago. 2015a.

IVO, Andressa Aita; HYPOLITO, Álvaro Moreira. Políticas gerenciais em educação: efeitos sobre o trabalho docente. Currículo sem Fronteiras, v. 15, n. 2, 2015b. Disponível em: http://www.curriculosemfronteiras.org/vol15iss2articles/ivo-hypolito. pdf. Acesso em: 19 mar. 2009.

IVO, Andressa Aita; HYPOLITO, Álvaro Moreira. Políticas educacionais: gerencialismo, gestão educacional e gestão escolar. In: CORTE, Marilene Gabriel Dalla; MELLO, Andrelisa Goulart de (org.). Conselhos Municipais de Educação: configurações e [re]articulações no campo das políticas e gestão educacional. Curitiba: CRV, 2016. p. 123-137.

LEITE, Maria Cecília Lorea; HYPOLITO, Álvaro Moreira. Modos de gestão, currículo e desempenho escolar. Revista Espaço do Currículo, v. 3, n. 2, p. 535-547, set./mar. 2011.

LEITE, Maria Cecília Lorea. et al. Gestión escolar democrática: una construcción contextualizada en escuelas municipales de la ciudad de Pelotas, RS, Brasil. Revista Mexicana de Investigación Educativa, v. 17, n. 52, p. 89-113, jan./mar. 2012.

MOLL, Roberto. Diferenças entre neoliberalismo e neoconservadorismo: duas faces da mesma moeda? São Paulo, 2015. Disponível em: http:// unesp.br/semdiplomacia/opiniao/2015/43. Acesso em: 11 maio 2016.

NÓVOA, António. Para o estudo sócio-histórico da gênese e desenvolvimento da profissão docente. Teoria \& Educação, Porto Alegre, n. 4, p. 109-139, 1991.

POPKEWITZ, Thomas; LINDBLAD, Sverker. A fundamentação estatística, o governo da educação e a inclusão e exclusão sociais. Educação \& Sociedade, v. 37, n. 136, p. 727-754, jul./set. 2016.

STRECK, Danilo Romeu. Cinco razões para dialogar com Paulo Freire. Revista e-curriculum, São Paulo, v. 7, n. 3, 2011. Disponível em: http://revistas. pucsp.br/curriculum/article/view/7595/5545. Acesso em: 15 mar. 2019.

TAMBARA, Elomar A. C. Profissionalização, escolar normal, feminização e feminilização: magistério sul -rio-grandense de instrução pública: 1880/1935. In: HYPOLITO, Álvaro Moreira; VIEIRA, Jarbas Santos; GARCIA, Maria Manuela A. Trabalho docente: formação e identidades. Pelotas, RS: Seiva, 2002. p. 67-97.

Recebido em: 10/03/2019

Aprovado em: 02/08/2019

(cc) EY-NC Este é um artigo publicado em acesso aberto sob uma licença Creative Commons. 